\title{
USING AN ARTISTIC APPROACH TO THE TEACHING OF NON- EUCLIDEAN GEOMETRY IN A PROFESSIONAL DEVELOPMENT COURSE FOR MATHEMATICS TEACHERS
}

\author{
Andreia Hall', Isabel Brás ${ }^{1}$, Sónia Pais² \\ ${ }^{1}$ CIDMA, Center for Research and Development in Mathematics and Applications, \\ University of Aveiro (PORTUGAL) \\ ${ }^{2}$ CITUR - Centro de Investigação, Desenvolvimento e Inovação em Turismo, Polytechnic \\ Institute of Leiria (PORTUGAL)
}

\begin{abstract}
Elliot Eisner (1933-2014), a pioneer in arts education, suggested that an artistic approach to education could improve its quality and lead to a new vision for teaching and learning [1]. This is true for any subject, including mathematics. Geometry related topics make a perfect setting for a deeper contribution of art to education and allow for a complete symbiosis between the teaching of mathematics and an artistic education. One such topic is the study of non-Euclidean geometry which is now briefly addressed in the middle school mathematics curriculum in Portugal [2]. We believe that the learning and teaching of non-Euclidean geometry can be facilitated by taking the role of an artist and creating works of art, eventually inspired by renowned artists such as M.C. Escher. In this paper, we present some results of a professional development course for mathematics teachers where the participants studied basic non-Euclidean geometry concepts and created ceramic pieces using the Poincaré disk. The course took place in a Portuguese university, from January to March 2018, and involved 20 teachers of grades 1 to 12 .
\end{abstract}

The authors have developed a qualitative case study to evaluate how an artistic approach to the teaching of non-Euclidean geometry is perceived, by the mathematics teachers, as a contribution to the learning process. Overall, the activities developed have proved to be successful examples of interdisciplinary methodologies that bring into the teaching of mathematics usual procedures in the teaching of the arts. Moreover, the artistic approach followed during the course helped the teachers develop their geometric competences concerning non-Euclidean geometry in a more solid appropriation and application of the geometric concepts involved.

Keywords: professional development; art and mathematics; non-Euclidean geometry; mathematics education.

\section{INTRODUCTION}

Mathematics classes in schools are usually described by students as being uninteresting and boring [3]. This is not a recent problem: more than a decade ago, Gadanidis and Hoogland [4] described the mathematics that is experienced in school as being flat-lined and, over 30 years ago, Davis and Hersh [5] described mathematics classes as being dry as dust. Dietiker [6] refers that, in spite of several curricular reforms (mostly conformed to content revisions), students commonly experience mathematics as being uninspiring and dull.

Many researchers have tried to provide solutions and suggestions to deal with this problem. Elliot Eisner, a pioneer in arts education, believed that a conception of practice rooted in the arts should contribute to the improvement of both the means and the ends of education [1].

Engaging students in the classroom is a fundamental task for an effective and fulfilling learning experience [3]. In the arts, engagement tends to be secured by the aesthetic satisfactions obtained from the work itself [1]. The work being created presents natural challenges which are related to part of these satisfactions:

Materials resist the maker; they have to be crafted and this requires an intense focus on the modulation of forms as they emerge in a material being processes. This focus is so intense that all sense of time is lost. The work and the worker become one. (p.14)

Eisner [1] believes that the feeling of vitality and the surge of emotion we feel when experiencing an art can be embedded in the ideas teachers explore with students and in the appetite for learning that 
teachers stimulate: "In the long run, these are the satisfactions that matter most because they are the only ones that ensure that what we teach students will want to pursue voluntarily after the artificial incentives so ubiquitous in our schools are long forgotten" (p.14-15).

Geometry related topics make a perfect setting for a deeper contribution of art to education and allow for a complete symbiosis between the teaching of mathematics and an artistic education. One such topic is the study of non-Euclidean geometry which is now briefly addressed in the middle school mathematics curriculum in Portugal [2].

Today's fast changing pace allied to the complexity of mathematics teaching practices place extraordinary demands on practicing teachers [3]. Professional development is an important means to help teachers find ways to meet these demands. For almost thirty years, the mathematics education community has made a continuous effort to change teaching practices towards being more cognitively demanding, conceptually oriented and student centred [7].

A lot of research on teacher's professional development has been done in the past years. Borko et al. [8] highlight the recent shifts in professional development methodologies. These shifts are somewhat related to recent shifts in the prominence of ideas about the nature of cognition, learning and teaching. As the authors refer, professional development should move away from a rigidly structured in-service training model towards approaches grounded in classroom practice and involving the formation of professional learning communities. Indeed, as Higgings and Parsons [9] wrote, "professional learning opportunities for teachers need to be situated in the teacher's context of practice and relevant to the teaching and learning needs of teachers and students" (p.232). These learning opportunities should focus on the real context of the classroom and be integrated into the teachers' everyday work.

In this paper, we present some results of a professional development course for mathematics teachers where the participants studied basic non-Euclidean geometry concepts and created ceramic panels using the Poincaré disk.

\section{NON-EUCLIDEAN GEOMETRY}

A prominent contribution to the exploration of artistic tessellations was given by M.C. Escher, a Dutch graphic artist who lived from 1898 to 1972 . Despite not being a mathematician, his work is strongly influenced by mathematical concepts and Escher made his own mathematical incursions in order to achieve his artistic purposes. Some of his works are based on hyperbolic geometry, in particular on tilings of the Poincaré disk. Examples of such art works are: Circle Limit with Butterflies (1950), Circle Limit I (1958), Circle Limit III (1959) and Circle Limit IV (1960) (see https://www.wikiart.org/en/m-cescher/all-works\#!\#filterName:Series_circle-limit,resultType:masonry).

The Poincare disk is an incidence geometry [10, p.17] where points are the points inside the open unitary disk and lines are of two types: diameters of the disk and arcs of orthogonal circumferences to the disk, lying in the disk interior. As in other plane geometry, two lines are said to be parallel if they do not have common points. Thus, in the Poincaré disk given a line $I$ and a point $P$, not belonging to the line, there exist an infinite number of lines passing through $P$ that are parallel to $I$. For that reason, the Poincaré disk is a model for hyperbolic geometry, see for instance [10, p. 331].

In fact, non-Euclidean geometries are geometries where the Euclidean Parallel Postulate is replaced. Recall that, the Euclidean Parallel Postulate states that for every line I and every point $P$ that does not lie on $I$, there exists a unique line $m$ such that $P$ lies on $m$ and $I$ and $m$ are parallel [10].

In a hyperbolic geometry, as in the Poincaré disk, this axiom is replaced by the Hiperbolic Parallel Postulate that states that for every line I and every point $P$ that does not lie on I, there are at least two lines $m$ an $n$ such that $P$ lies on both $m$ and $n$ and both are parallel to I [10].

The other parallel postulate that can replace the Euclidean one is the Elliptic Parallel Postulate that states that for every line I and every point $P$ that does not lie on I, there is no line $m$ such that $P$ lies on $m$ and $m$ is parallel to I [10]. One of the most important models for Elliptic Geometry is the unitary sphere, where points are the points on the surface of the sphere and the lines are the big circles. In this model there are no parallel lines. 


\section{METHODOLOGY}

\subsection{Methodological options}

The research question underlying this study is:

How is an artistic approach to the teaching of non-Euclidean geometry perceived, by mathematics teachers, as a contribution to the learning process?

As a consequence, the following objectives were defined:

Has the use of this artistic approach contributed to:

- a more solid appropriation and application of the concepts involved;

- making the learning process more interesting?

In this perspective, a mixed case study was developed (quantitative and qualitative, based on a logic of complementarity), grounded on a pragmatic paradigm and case study design ([11],[12] and [13]). The study was undertaken in a Portuguese higher education institution involving the participants of a professional development course intended for mathematics teachers. The teachers responsible for the course in question are simultaneously researchers of this study.

In order to develop this experience, the techniques of inquiry, direct observation and documental collection were applied and the following instruments were used: final questionnaire; field notes and interviews.

\subsection{Description of the course}

The professional development course addressed in this paper is part of a set of professional development courses for mathematics teachers promoted over the last years following the ideas presented in the first section of this paper. In these courses we try to integrate the activities into the teachers' everyday work, while at the same time provide an opportunity to both learn and have a fulfilling and gratifying experience. Following the ideas presented by Borko et al. [8], these courses are intended to be "opportunities grounded in a conception of learning to teach as a lifelong endeavour", that should be both pleasurable and rewarding. At the same time, we try to move towards Eisner's conception of a practice rooted in the arts. Teachers take on the role of an artist: they are given time to explore, to create and to surprise themselves.

The professional development course in focus was titled "Geometrias a torto e a direito" (Geometries in many ways) and took place in the University of Aveiro, in 2018, from January $5^{\text {th }}$ to March $23^{\text {rd }}$. Like all professional development courses for Portuguese teachers, it was acknowledged by the national scientific and pedagogical council for teacher's professional development (Conselho CientíficoPedagógico da Formação Contínua), and was registered with the number CCPFC/ACC - 92641/17. This course consisted of 25 hours of contact between all participants and had the collaboration of a ceramist who taught part of the course. The course had 20 participating teachers who taught mathematics from grades 1 to 12 . Given the wide range of grades taught and the specificity of each level of teaching, different activities were proposed for teachers of different levels (elementary and secondary).

In the first part of the course, some concepts were provided or recalled and related activities were carried out. The participants performed several tasks intended to deepen their knowledge on Geometry, with a special focus on non-Euclidean geometries. In addition they were given tasks to prepare them for the applied project they had to develop during the second part of the course. These tasks were designed, mainly, to explore elementary notions of the Poincaré disk as a model of Hiperbolic Geometry. The GeoGebra, a dynamic geometry software, was used since the tasks were of constructive nature and this software is specially suitable for educational purposes. The participants were invited to draw points, lines (parallel or not), polygons and to measure angles. Examples of art works from renowned artists using the Poincaré disk were shown and explored.

In the second part of the course the participants were asked to develop an individual project that put the theoretical concepts into practice. Each participant was challenged to create his own piece(s) of art. The final result was one or more glazed and colored ceramic pieces by each participant using the Poincaré disk. 


\section{RESULTS}

\subsection{Participants' outcomes}

In this section, photos of a selection of the art works produced are shown. The author of each work is identified in each case.

All participants were asked to project a ceramic piece using the Poincaré disk. Most projects were created using the software GeoGebra applying the concepts explored in the first part of the course, regarding the non-Euclidean geometries.

Figures 1 and 2 contain patterns with a lot of regularity (symmetry), based on tilings of the Poincaré disk with triangles. The pattern on the right of Figure 2 is a tiling of the disk using ideal triangles, but incomplete towards the border.
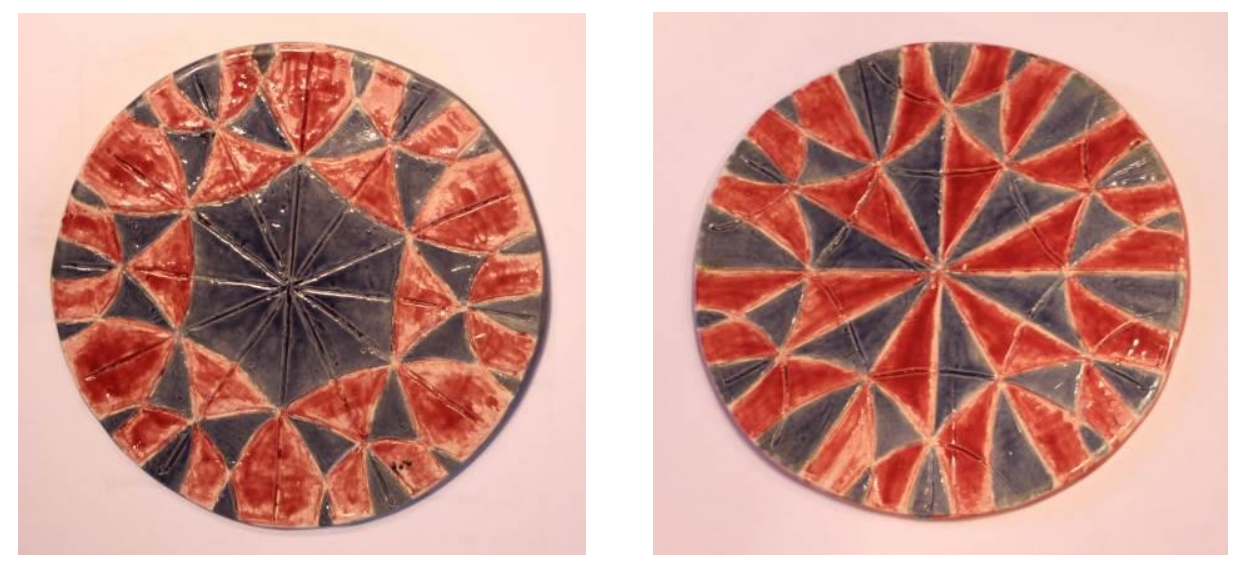

Figure 1. Creamic pieces by Ana Berta Póvoa.
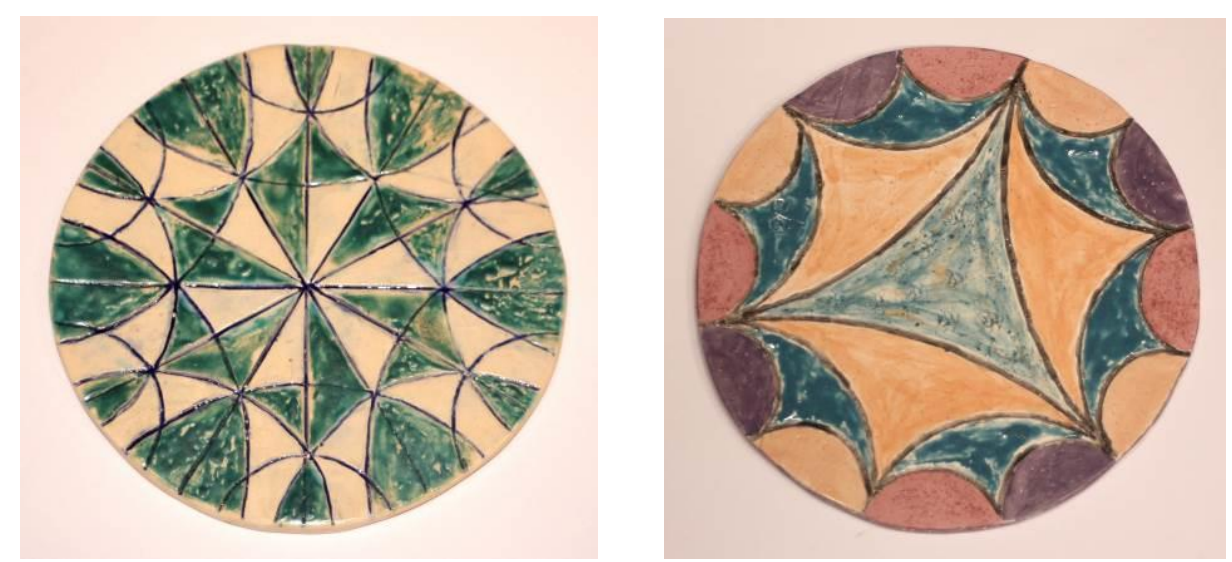

Figure 2. Ceramic pieces by Óscar Gomes (left) and Isabel Bebiano (right).

Figure 3 contains two designs made of parallel lines on the Poincaré disk. Both designs have reflection symmetry over a diameter. 

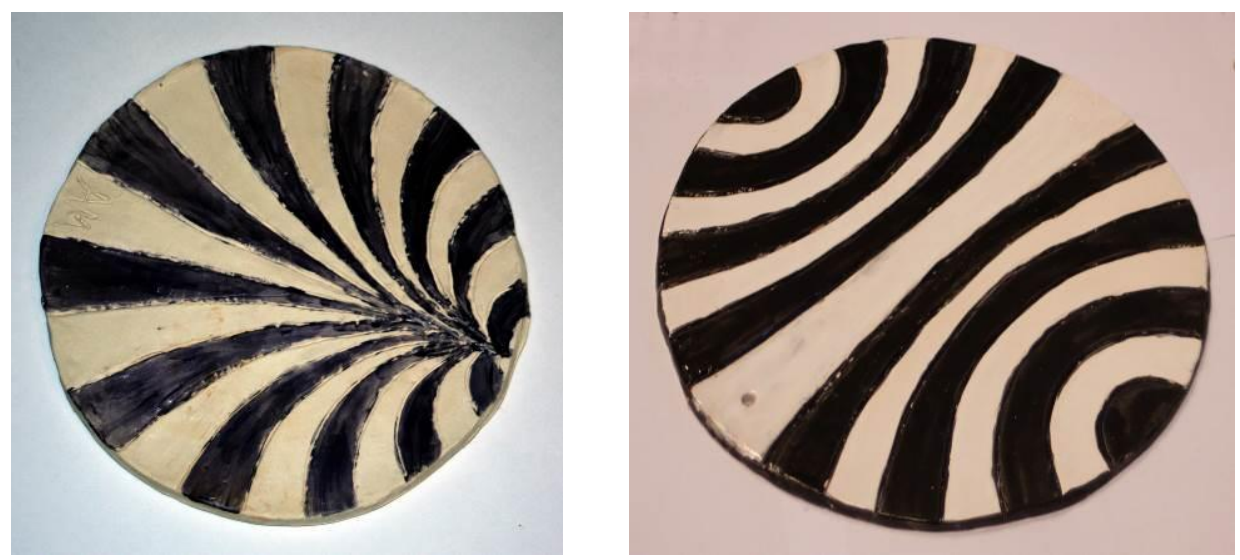

Figure 3. Ceramic pieces by Albertina Monteiro (left) and Paula Carvalho (right).

Figures 4 and 5 contain free designs using only lines on the Poincaré disk.
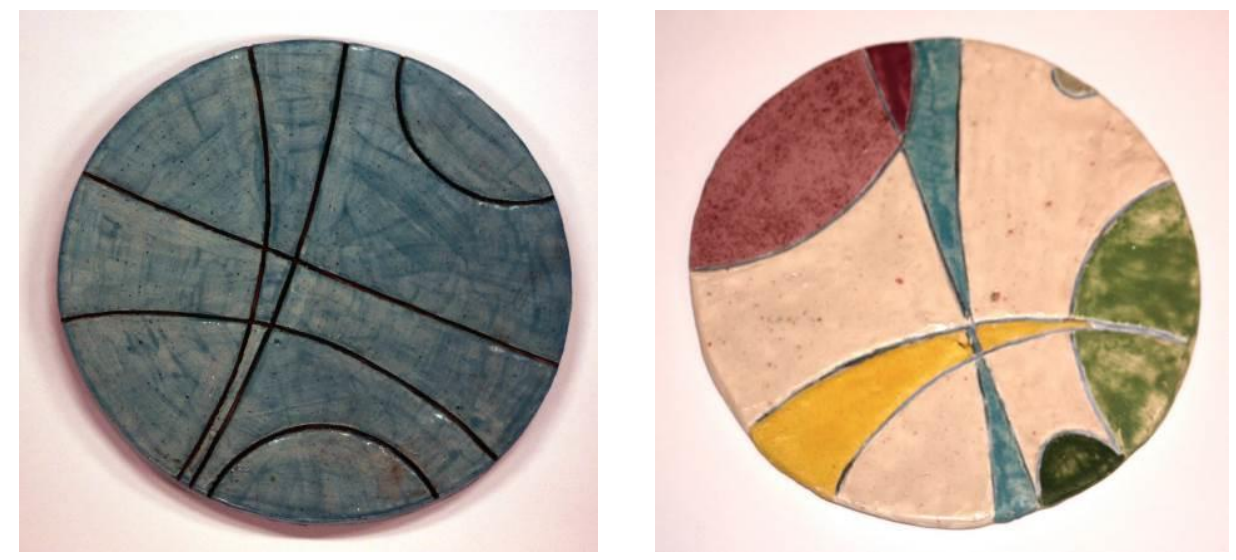

Figure 4. Ceramic pieces by Carla Machado (left) and Manuela Sousa (right).
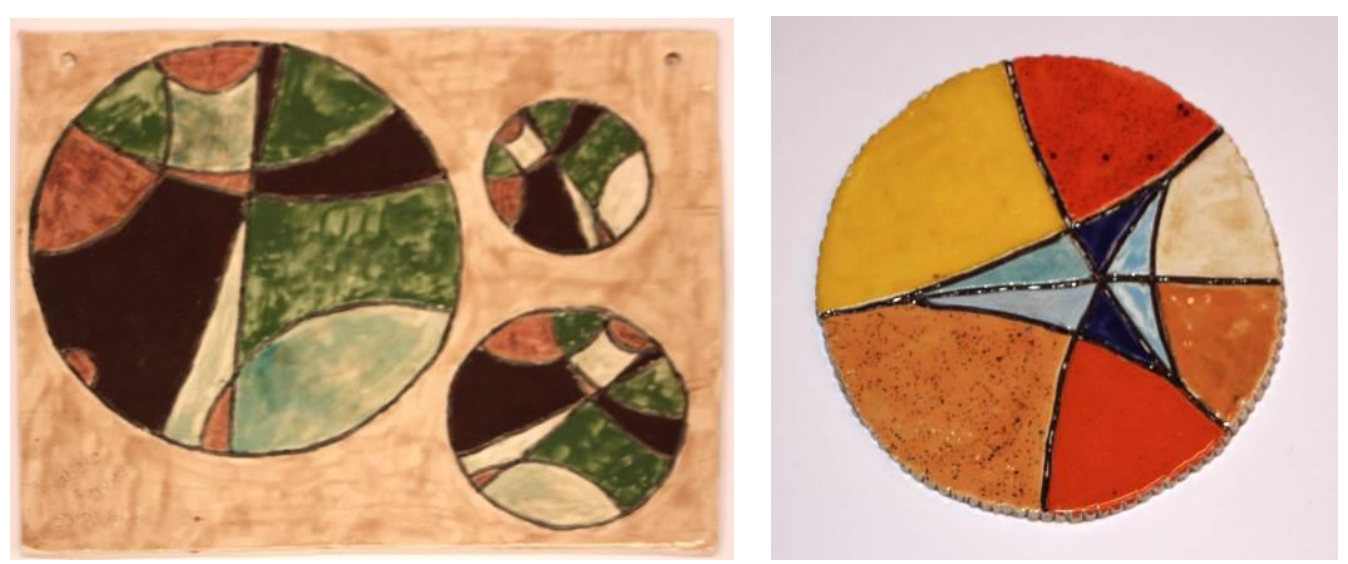

Figure 5. Ceramic pieces by Anabela Roque (left) and Rosa Ferreira (right).

\subsection{Other results}

This paper intends to analyse how an artistic approach to the teaching of non-Euclidean geometry is perceived, by the mathematics teachers, as a contribution to the learning process. To reach this goal, direct observation and field notes were the main instruments used. Through direct observation it can be concluded that the participants were deeply interested in performing the tasks, especially the final applied projects. The fact that they had a concrete goal to achieve - the development of an individual work of art - was an important source of motivation for and engagement with all the tasks. As the tasks were performed, we observed an increasing willingness to perform their own projects, though 
they also realized how difficult the challenge was since non-Euclidean Geometry is not a familiar topic for Mathematics teachers and is surprisingly different from the traditional Euclidean geometry.

A questionnaire was answered by the participants at the end of the course. Teachers were asked to answer through a four point Likert scale (1-"unsufficient"; 4-"very good") to the following questions:

1. Were the topics of the course relevant?

2. Were the objectives of the course met?

3. What is your overall satisfaction with the course?

Teachers were also asked to answer the following Yes/No questions:

4. Did the course meet your expectations?

5. Would you advise the course to other teachers?

Through the analysis of the questionnaires: Questions 1 was answered as "very good"(4) by all the respondents except two who answered "good"(3) and one who answered "sufficient"(2); Question 2 was answered as "very much"(4) by all respondents except three who answered "good"(3); Question 3 was answered as "very much" (4) by all respondents. Regarding question 4 and 5, all respondents answered Yes.

Finally, they were asked to state three positive aspects and three negative aspects of the course. The most frequent positive aspects stated were the practical projects, the good relationship between participants and supervisors and the mutual aid. Only three participants stated negative aspects and these were related to the distance they had to cover to come to the sessions.

From the analysis of the questionnaire, it can be concluded that there was a positive influence of the artistic approach used in the course towards a more solid appropriation and application of the geometric concepts involved. The obtained results are consistent with the filed notes registered by the teacher during the professional development course. Not only the participants' curiosity, motivation and enthusiasm was great and enduring but also their performance regarding both the preparatory geometry tasks and the artistic projects revealed a good appropriation of the concepts involved.

In this professional development course, an artistic approach to teaching and learning was facilitated, since each participant was given the opportunity to create a concrete piece of art that naturally produces an aesthetic satisfaction which in turn leads to a deep engagement with the work itself. As referred before, Eisner [1] considers that this strong engagement is so intense that the sense of time can be lost. As happened in previous professional development courses following the same type of approach, during this course the participants had the pleasure to witness, more than once, the loss of their sense of time while engaging with their creations.

\section{CONCLUSIONS}

The professional development course described in this paper sought to investigate how an artistic approach to the teaching of non-Euclidean geometry is perceived, by the mathematics teachers, as a contribution to the learning process.

The participants showed great commitment in the accomplishment of the proposed tasks and projects. Their performance (throughout the entire course) showed that they deepened and acquired new knowledge concerning non-Euclidean geometry. They also acquired or improved their competences regarding the use of GeoGebra.

The conclusions withdrawn from this study are in line with those reached by Hall and Pais [3]:

Overall, the activities developed have proved to be successful examples of interdisciplinary methodologies that bring into the teaching of mathematics usual procedures in the teaching of the arts, associated to the process of artistic creation. We believe that these teachers have been strengthened in their capacity to develop multidisciplinary tasks and projects with their students. The methodologies used, involving the interconnection between different areas, promote a positive attitude towards mathematics and thus foster the motivation to learn it.

The phase of development of artistic projects was particularly rewarding, since the participants were involved in every step of the process, dedicating with pleasure all the necessary time to its 
accomplishment. Most of all, the participants showed enthusiasm and joy during the course and these are main ingredients for successful teaching and learning.

The results of the present research show that the selected approach is positively perceived, by the participants, as contribution to the teaching and learning process non-Euclidean geometry. The questionnaire filled out at the end of the course showed that the overall evaluation of the course was very positive and allows us to conclude that its goals were accomplished.

Overall, it can be concluded that both objectives established for this research were positively met since:

- the artistic approach followed during the course helped the teachers develop their geometric competences concerning non-Euclidean geometries,

- from what the researchers observed during the course, the participants were interested and motivated, which is also reinforced by the analysis of the answers to question 3 of the applied questionnaire..

Regarding the research question - How is an artistic approach to the teaching of non-Euclidean geometry perceived, by mathematics teachers, as a contribution to the learning process? - this study suggests that the teachers perceived the contribution as a positive one.

\section{ACKNOWLEDGEMENTS}

This work was supported in part by the Portuguese Foundation for Science and Technology (FCTFundação para a Ciência e a Tecnologia), through CIDMA - Center for Research and Development in Mathematics and Applications, within project UID/MAT/04106/2019.

\section{REFERENCES}

[1] E. W. Eisner, "What can education learn from the arts about the practice of education?" Journal of Curriculum and Supervision, vol. 18, no. 1, pp. 4-16, 2002.

[2] A. Bivar, C. Grosso, F. Oliveira \& M.C. Timóteo, Programa e Metas Curriculares de Matemática - Ensino Básico. Ministério da Educação e Ciência, 2013 [E-Reader Version]. Retrieved from http://www.dge.mec.pt/sites/default/files/Basico/Metas/Matematica/programa_matematica_basic o.pdf.

[3] A. Hall \& S. Pais, "Learning and teaching symmetry by creating ceramic panels with Escher type tessellations," Indagatio Didactica, vol. 10, no. 2, pp. 85-107, 2018.

[4] G. Gadanidis, \& C. Hoogland, "The aesthetic in mathematics as story," Canadian Journal of Science, Mathematics and Technology Education, vol. 3, no. 4, pp. 487-498, 2003.

[5] P. J. Davis \& R. Hersh, The Mathematical Experience. Boston-Basel-Stuttgart: Birkhäuser Verlag, 1981.

[6] L. Dietiker, "What Mathematics Education Can Learn from Art: The Assumptions, Values, and Vision of Mathematics Education," Journal of Education, vol. 195, no. 1, pp. 1-10, 2015.

[7] E. Heyd-Metzuyanim, M. Tabach \& T. Nachlieli, "Opportunities for learning given to prospective mathematics teachers: between ritual and explorative instruction," Journal of Mathematics Teacher Education vol. 19, pp. 547-574, 2016.

[8] H. Borko, J. Jacobs, K. Koellner, "Contemporary approaches to teacher professional development." In: Peterson, P., Baker, E., \& McGaw, B. (eds.), International Encyclopedia of Education, vol. 7, pp. 548-556. Oxford: Elsevier, 2010.

[9] J. Higgins \& R. Parsons, "A successful professional development model in mathematics: A system-wide New Zealand case," Journal of Teacher Education, vol. 60, no. 3, pp. 231-242, 2009.

[10] G.A. Venema, Foundations of Geometry. Upper Saddle River/New Jersey: Pearson Prentice Hall, 2002. 
[11] H. Carmo \& M. Ferreira, Metodologia da Investigação - Guia para Auto-Aprendizagem. Lisboa: Universidade Aberta, 1998.

[12] J. Ponte, (2006). "Estudos de caso em educação matemática," Bolema, vol. 25, pp. 105-132, 2006.

[13] Yin, R. (1994). Case Study Research. Design and Methods. Thousand Oaks: Sage Publications. 